\title{
Pkm Kelompok Industri Kreatif "Pengrajin Limbah Kayu" Untuk Memperkuat Ekonomi Lokal Di Kecamatan Mayangan Kota Probolinggo
}

\author{
Ludfi Arya Wardana ${ }^{1}$, Misdiyanto $^{2}$ \\ Universitas Panca Marga Probolinggo \\ ludfiaryawardana@upm.ac.id,misdiyanto@upm.ac.id
}

\section{ARTICLE INFO}

Keyword:

wood waste, lasser wood cutting machine, website marketing

\begin{abstract}
$A B S T R A C T$
The aim of the PKM program is aimed at the productive community (UKM) in the district of Probolinggo, Mayangan District. UKM is meant to move in processing wood waste belonging to Mr Eko Nur Widyanto having the address at Mayangan District, Probolinggo City. The problems are namely, the length of the process of designing, cutting and refining wood that is done manually with human power. The lack of optimal network marketing done manually is only an HP device with a Facebook application. The concrete solution made by proponents to overcome the problem is by making and designing lasser wood cutting machines, website marketing and website usage training. The output of this program is lasser wood cutting machines, website marketing, website marketing training.
\end{abstract}

\section{PENDAHULUAN}

Industri kreatif pengrajin limbah kayu merupakan usaha yang memanfaatkan limbah kayu yang melimpah yang ada di sekitar Probolinggo. Limbah kayu ini dihasilkan dari kerjasama penanaman pohon antara masyarakat di sekitar Probolinggo dengan PT. Kutai Timber Indonesia/KTI (Jl. Tanjung Tembaga Baru, Mayangan, Probolinggo, Kota Probolinggo, Jawa Timur) yang bergerak dibidang penmanfaatan kayu ekspor. Menurut Bapak Eko Nur Widyanto, pengusaha kerajinan limbah kayu, beliau membuka usaha ini dimulai pada tahun 2015 yang melihat banyak ranting-ranting atau potongan- potongan kayu sisa potongan pabrik PT. KTI yang berserakan di perkebunan milik masyarakat di sekitar Probolinggo. Potongan limbah kayu tersebut dibiarkan tanpa ada yang mengurus dan biasanya hanya dibuat kayu bakar oleh masyarakat. Hal ini sejalan dengan Rachman \& Malik (2011) mengemukakan bahwa limbah potongan kayu dalam bentuk dan ukuran tertentu yang seharusnya masih bisa dimanfaatkan tetapi ditinggalkan karena keterbatasan tingkat teknologi pengolahan kayu yang ada pada waktu itu.

Produk yang dihasilkan dari limbah kayu berupa potongan-potongan kayu dapat dimanfaatkan berbagai meja akar kayu, kursi, rak, hiasan, lukisan yang mempunyai nilai seni yang tinggi. Hal ini sejalan dengan Iriawan (2013) mengemukakan bahwa limbah kayu tergolong limbah yang mempunyai nilai kemanfaatan yang tinggi jika dimanfatkan menjadi kerajinan. Bahkan banyak masyarakat yang dari Probolinggo mencari produkproduk tersebut untuk dijadikan furniture dirumahnya. Sejak itu, banyak pengrajin limbah kayu yang bermunculan di sekitar Probolinggo sehingga menjadi salah satu khas Probolinggo.

Dilihat dari aspek ekonomi, usaha kerajinan limbah kayu sangat menguntungkan bagi masyarakat sekitar, karena permintaan yang banyak tetapi dari bahan dasar yang tanpa modal yaitu dari limbah kayu dan dapat mempunyai nilai jual yang tinggi. Keberadaaan pengrajin limbah kayu ini dapat memberikan keuntungan yang besar bagi masyarakat berupa peluang pasar sehingga dapat memperkuat ekonomi lokal masyarakat khususnya 
Kecamatan Kedopok Kota Probolinggo. Kerajinan limbah kayu khas Probolinggo ini terbuat dari limbah kayu jati, mahoni, meranti, sengon yang mempunyai kualitas tinggi sehingga hasil kualitasnya mampu bersaing di era ekonomi pasar bebas ini. Hal ini sejalan Arinana, Haneda, dkk (2010) mengatakan bahwa olahan produksi kayu Indonesia mampu menembus pasar internasional dengan berbagai bentuk seperti kerajinan hiasan lampu, dinding dan kursi meja ukir, lukisan dari kayu

Dilihat dari aspek sosial, usaha kerajinan limbah kayu masih bersifat home industry diharapkan dapat menyerap tenaga kerja yang ada di lingkungan sekitar. Hal ini sejalan dengan UU No. 20 Tahun 2008 mengenai usaha mikro, kecil dan menengah, usaha mikro merupakan usaha produktif milik orang perorangan dan/atau bahan usaha yang memenuhi kriteria usaha mikro. Banyak masyarakat yang belum mempunyai pekerjaan khususnya para kalangan bawah yang minim pendidikan dan keterampilan. Secara tidak langsung keberadaan home industry ini mempengaruhi penciptaan lapangan kerja sehingga mengurangi pengangguran dan kesenjangan sosial yang ada.

Pengusaha pengrajin limbah kayu milik Bapak Eko Nur Widyanto merupakan mitra dalam Program Kemitraan Masyarakat. Profil mitra yaitu, nama Eko Nur Widyanto yang beralamat Jalan Nusa Dua Kecamatan Mayangan Kota Probolinggo. Usaha ini mulai berdiri Juli 2015. Jumlah karyawan 5 orang yaitu, Pak Eko Nur Widyanto, Holmes, Dani, Solu, Alpin. Rata-rata produksi kerajinan limbah kayu adalah 5 kerajinan/hari. Adapun proses produksi dalam kerajinan limbah kayu sebagai berikut.

Limbah kayu diperoleh dari sisa-sisa pemotongan kayu dari hasil kerjasama PT.KTI dan masyarakat yang sudah tidak terpakai. Ukuran kayu sekitar rata-rata $50 \mathrm{~cm}$

- 100cm dan untuk harga bahan baku ini hanya ongkos angkut sekitar Rp. 200.000/pick up dari perkebunan sampai tempat produksi. Ketersediaan bahan baku melimpah sehingga sehingga ketersediaan bahan baku selalu ada.

Proses pembuatan desain kerajinan seperti lukisan kayu, hiasan, gantungan kunci merupakan langkah awal yang harus dilakukan. Dimulai dari memilih bahan limbah kayu yang ukuran sekitar panjang $50 \mathrm{~cm}$, lebar $40 \mathrm{~cm}$. Selanjutnya, diamplas agar halus setelah itu diberikan desain yang sesuai dengan model potongan kayu tersebut. Setelah mendesain bahan baku sesuai ukuran yang diinginkan, maka langkah selanjutnya memotong limbah kayu menjadi kecil-kecil lebar $5 \mathrm{~cm}$ dan panjang $12 \mathrm{~cm}$.

Ukuran diameter memang sengaja tidak sama karena agar memberikan nilai estetika pada kerajinan. Proses penghalusan terlalu lama karena memakai alat manual amplas sehingga untuk mempercepat produksi belum memadai. Setelah proses pemotongan selanjutnya proses penghalus ke media tempel (lukisan, hiasan dinding, dll). Proses penghalusan dan melukis dengan teknik bakar dilakukan dengan pyrograph.

Setelah limbah kayu dan media telah tertempel didiamkan sekitar \pm 5 jam agar lem bisa tertempel dengan kuat. Selanjutnya itu proses dilakukan amplas halus sebelum dilakukan pengecatan plitur. Pemlituran dilakukan sebanyak 3 kali untuk mendapatkan hasil yang maksimal.

Permasalahan yang dihadapi mitra adalah bagaimana memperluas jaringan pemasaran sehingga bisa menjual setiap waktu. Selain itu, pengembangan pemasaran dengan memperluas jaringan ini diperlukan agar keberadaan pengrajin kreasi limbah kayu ini diketahui dunia luar tidak hanya diketahui masyarakat Probolinggo saja. Jaringan atau networking sangat diperlukan, karena berdasarkan pengalama mengikuti pameran yang 
diadakan tiap tahun oleh pemerintah propinsi, membantu peningkatan omzet. Menurut peneliti, dengan kualitas hasil kerajinan kreasi limbah kayu berupa meja kursi, hiasan dinding, hiasan lampu, dll yang bagus, artistik, baik dari segi desain, pola penempelan kayu, pengecatan plitur, maka produk ini mampu bersaing di pasar internasional sebagai produk kerajinan khas Indonesia.

Keterbatasan jaringan atau belum dikenalnya produksi produk kerajinan kreasi limbah kayu masyarakat luas merupakan termasuk permasalahan mitra. Mitra merasa bahwa penjualan hanya dilakukan daerah Probolinggo saja. Hal ini disebabkan oleh keterbatasan waktu, tenaga serta biaya yang dimiliki mitra untuk mempromosikan produk seperti dilakukan pada saat pameran- pameran. Pengalaman yang dimiliki mitra pada saat melakukan pameran, pembeli dari luar kota merasa antusias dengan kualitas kain dan harga yang bersaing. Namun demikian kendala adalah jarak, waktu, tenaga dan biaya untuk menenuhi antusiasme pembeli dari luar kota.

Bapak Eko Nur Widyanto, sudah mencoba memasarkan lewat facebook, hasilnya lumayan baik tanggapan dari pembeli luar kota. Namun karena sarana yang digunakan hanya lewat hp dengan kapasitas terbatas maka kadang terkendala oleh jaringan internet. Pesanan yang mestinya sudah dikirim, belum terkirim karena beritanya baru sampai. Kendala- kendala inilah yang ditemui untuk mengembangkan pemasaran.

Permasalahan yang ada, tim pengusul dan mitra telah berdiskusi dan sepakat untuk membuat skala prioritas permasalahan-permasalahan yang ada yang akan diselesaikan.

a. Lamanya proses pendesain, pemotong dan penghalusan kayu yang dilakukan secara manual dengan tenaga manusia.

b. Belum optimalnya jaringan pemasaran yang dilakukan manual hanya perangkat hp dengan aplikasi facebook.

\section{PELAKSAAAN DAN METODE}

Pelaksanaan pengabdian kepada masyarakat dilakukan mulai Maret 2019. Sasarannya yaitu mitra UMKM "Dolind Indonesia" beralamat di Kecamatan Mayangan Kota Probolinggo. Pemilik UMKM ini bernama Bapak Eko Nur Widyanto dengan mempunyai 5 karyawan.

Permasalahan yang sudah diidentifikasi dan disimpulkan, maka akan dicari solusinya dengan pendekatan tepat sehingga permasalahan yang dipaparkan dapat teratasi dengan baik. Tahapan-tahapan yang harus dilalui untuk mencapai solusi yaitu:

a. Diskusi dan Pengumpulan Referensi Diskusi antara tim pelaksana dan mitra tentang solusi permasalahan yang ada.

Mengumpulkan referensi tentang pembuatan mesin pendesain, pemotong dan penghalus. Mengumpulkan referensi tentang model- model pemasaran online dalam bentuk website yang akan diberikan kepada mitra sebagai pelaku usaha.

b. Membuat Desain Mesin Pendesain, pemotong dan penghalus dan Desain Website Merancang atau mendesain mesin pendesain, pemotong dan penghalus dan mendesain website pemasaran yang akan digunakan mitra.

c. Uji Coba Mesin dan Website Pemasaran Menguji coba mesin pendesain, pemotong dan penghalus untuk mengecek kemampuan dalam menghaluskan kayu. Menguji coba 
website pemasaran yang sudah dibuat pada mitra untuk mengecek kemampuan website tersebut dalam membuat jaringan calon konsumen.

d. Melaksanakan Pelatihan Keterampilan Komputer Berbasis Internet

Melatih mitra mengenai komputer berbasis internet dan penggunaan website pemasaran. Pelatihan ini bertujuan untuk partisipasi mitra sehingga efektif dalam pelaksanaan program.

Beberapa tahapan di atas merupakan tahapan untuk mecapai solusi terbaik dari permasalahan priorotas yang disepakati oleh mitra. Solusi tersebut yaitu:

a. Mesin pemotong kayu lasser dengan spesifikasi sebagai berikut:

1. Cutting Engraving Area : $200 \times 300 \mathrm{~mm}$

2. Cutting Speed : : $0-18 \mathrm{~mm} / \mathrm{second}$

3. Engraving Speed $\quad: 0-180 \mathrm{~mm} / \mathrm{second}$

4. Laser Power : $15 \mathrm{w}$

5. Motor type : stepper motor

b. Website pemasaran berbasis internet dengan spesifikasi sebagai berikut:

1. Usability : tinggi

2. Sistem navigasi : mudah dipahami pengunjung

3. Graphic desain (grafis, layout, warna, bentuk typografi) : menarik pengunjung

4. Content : perbaruan berkala

5. Kompatibilitas browser : mozila, opera, google chrome

\section{HASIL DAN PEMBAHASAN Hasil Karya Utama}

Pelaksanaan kegiatan Program Kemitraan Masyarakat (PKM) dengan judul PKM Kelompok Industri Kreatif "Pengrajin Limbah Kayu" untuk Memperkuat Ekonomi Lokal Di Kecamatan Mayangan Kota Probolinggo dengan baik. Kegiatan program ini dipastikan diterima proposalnya dan tanda tangan kontrak dengan DRPM Kemenristekdikti melalui LPPM UPM Probolinggo. Tim pelaksana tediri dari satu ketua tim dan satu anggota tim yang dibantu oleh dua mahasiswa sebagai administrasi dan desain grafis. Adapun kegiatan yang telah dilakukan sebagai berikut:

\section{a. Diskusi dan Pengumpulan Referensi}

Diskusi antara tim pelaksana dan mitra tentang solusi permasalahan yang ada. Mengumpulkan referensi tentang pembuatan mesin pendesain, pemotong dan penghalus. Mengumpulkan referensi tentang model-model pemasaran online dalam bentuk website yang akan diberikan kepada mitra sebagai pelaku usaha.

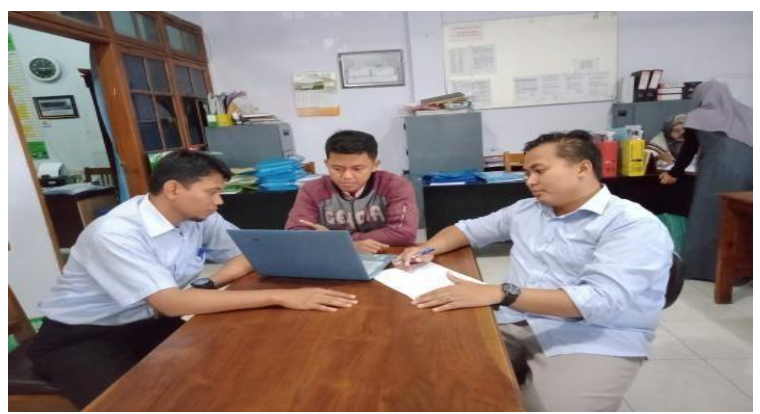

Gambar 1. Koordinasi Tim dengan Mitra 
b. Membuat Desain Mesin Pendesain, pemotong dan penghalus dan Desain Website

Merancang atau mendesain mesin pendesain, pemotong dan penghalus dan mendesain website pemasaran yang akan digunakan mitra.

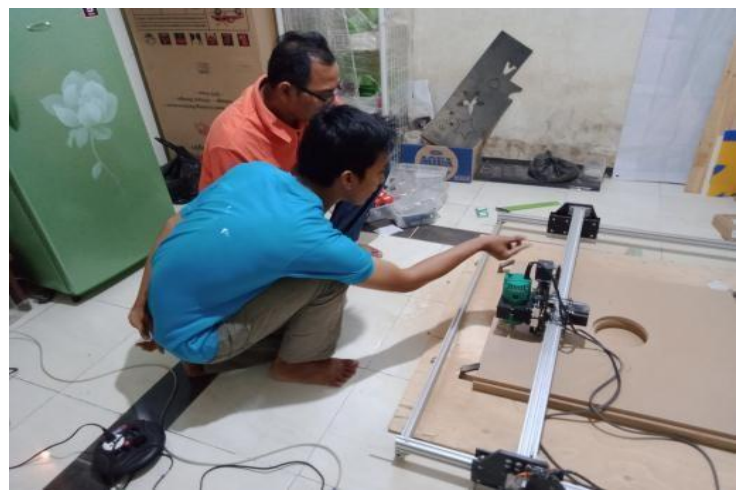

Gambar 2. Finalisasi Desain Mesin dan Websi

\section{c. Uji Coba Mesin dan Website Pemasaran}

Menguji coba mesin pendesain, pemotong dan penghalus untuk mengecek kemampuan dalam menghaluskan kayu. Menguji coba website pemasaran yang sudah dibuat pada mitra untuk mengecek kemampuan website tersebut dalam membuat jaringan calon konsumen.

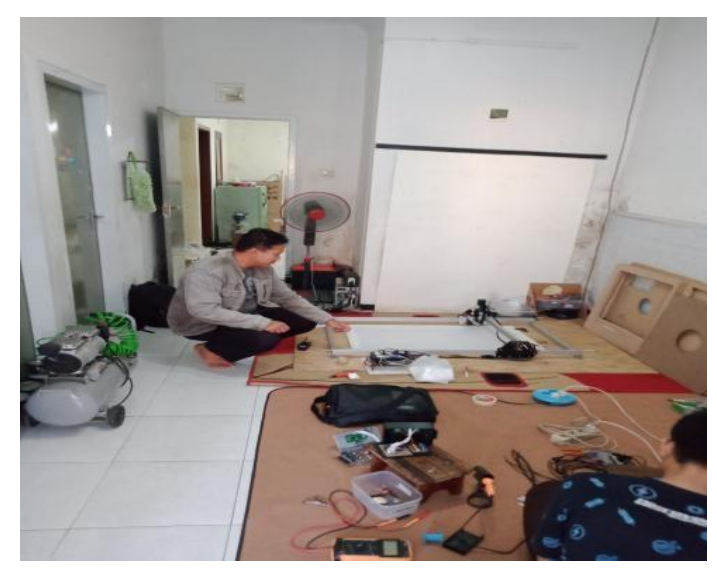

Gambar 3. Uji coba mesin pemotong kayu lasser

\section{d. Pelatihan Keterampilan Komputer Berbasis Internet}

Melatih mitra mengenai komputer berbasis internet dan penggunaan website pemasaran. Pelatihan ini bertujuan untuk partisipasi mitra sehingga efektif dalam pelaksanaan program.

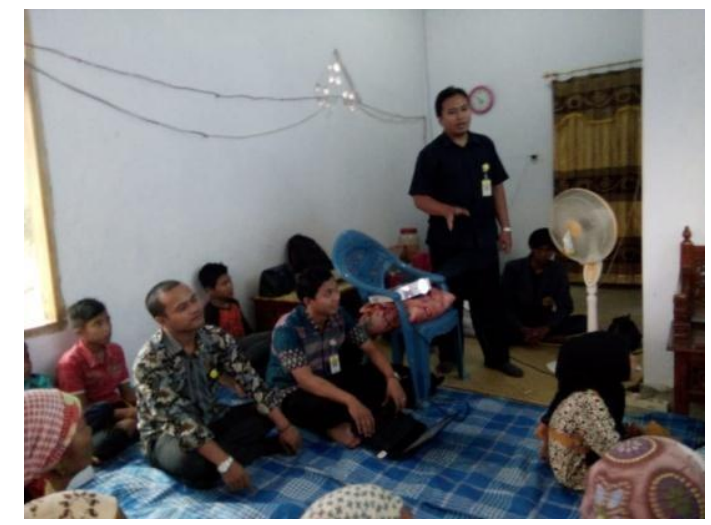

Gambar 4. Pelatihan Kegunaan Website ke Mitra 


\section{e. Monitoring dan Evaluasi}

Selanjutnya setelah mesin pemotong kayu lasser diserahkan kepada mitra, website pemasaran diserahkan akunnya ke mitra dan pelaksanaan pelatihan penggunaan website pemasaran maka dilakukan monitoring dan evaluasi. Tujuan montoring evaluasi adalah untuk mengetahui apakah mesin tersebut berfungsi dengan baik dan bisa bertahan lama, melihat pemasaran produk dari website pemasaran dan kendala-kendala di lapangan. Monitoring dilakukan secara bertahap yaitu satu bulan sekali. Selain itu, monitoring secara isindental dengan membuka lama website pemasaran. Hal ini dilakukan untuk melatih mitra agar lebih maju dan produktif.

\section{Pembahasan}

Produk-produk yang sudah dicapai dan dimanfaatkan oleh mitra mempunyai keunggulan dan kelemahan masing-masing. Mesin pemotong kayu lasser mempunyai keunggulan memotong dan mendesain kayu tanpa manual sehingga dapat lebih efisien, kelemahannya yaitu tidak semua orang bisa mengoperasikan mesin tersebut.

Website pemasaran mempunyai keunggulan dapat memasarkan lebih efektif dalam jaringan/internet sehingga produk dapat dilihat seluruh dunia. Hal ini untuk menyiapkan jika orang pesan dan ingin melihat produk lebih jauh kita arahkan ke galery pada website. Kelemahannya website ini selalu uptodate sehingga harus memasukan terus produk terbaru dari jenis karya yang sama.

Paparan di atan menunjukan bahwa limbah kayu mempunyai manfaat sangat baik untuk didaur ulang sehingga menghasilkan karya-karya yang mempunyai nilai ekonomis. Hal ini sejalan dengan dengan Iriawan (2013) mengemukakan bahwa limbah kayu tergolong limbah yang mempunyai nilai kemanfaatan yang tinggi jika dimanfatkan menjadi kerajinan. Penjelasan tersebut jelas bahwa masih dapat dikreasikan lagi limbahlimbah kayu yang ada untuk karya yang lain.

Capaian luaran yang dihasilkan dari kegiatan PKM ini berupa:

1) published/accepted publikasi ilmiah jurnal,

2) publikasi pada media masa cetak/online,

3) unggahan pelaksanaan kegiatan,

4) peningkatan omset produk meningkatkan.

\section{Penutup Simpulan}

Paparan di atas merupakan hasil pelaksanaan PKM, hal ini dapat disimpulkan sebagai berikut.

1. Mesin pemotong kayu lasser telah ditransfer ke mitra bekerja dengan baik sesuai dengan fungsi yang diharapkan.

2. Setelah penggunaan mesin pemotong kayu lasser mitra merasa terbantu dalam memotong dan mendesain kayu tanpa manual.

3. Website pemasaran telah ditransfer ke mitra bekerja dengan baik sesuai dengan fungsi yang diharapkan. 
4. Pelatihan penggunan website pemasaran telah dilakukan kepada mitra sehingga mitra dapat menggunakan website secara optimal.

5. Setelah penggunaan website pemasaran mitra merasa terbantu dalam pemasaran tidak terbatas pada facebook dan handphone.

\section{Saran}

Saran pemanfaatan dari mesin pemotong kayu lasser dan website sudah optimal, hanya peningkatan keterampilan pengoperasian mesin dan pengelolaan website yang membutuhkan waktu pembiasaan. Website mempunyai kelemahan harus sering update produk karya sehingga dapat mempromosikan karya-karya baru dari mitra.

\section{Daftar Pustaka}

Arinana, Haneda, dkk. 2010. Eating Termites Palatability of Some Composition Baiting as Media Life Nematodes Entomopathogen. Prosiding Seminar Nasional Masyarakat Peneliti Kayu Indonesia XIII; Bali, 10-11 Nov 2010. Bali :

Masyarakat Peneliti Kayu Indonesia. hlm 321-326.

Direktorat Jenderal Perkebunan. 2008. Undang-undang No. 20 Tahun 2008 mengenai usaha mikro, kecil dan menengah, usaha mikro. 28 Juni 2018.

Irawan. 2013. Volume dan klasifikasi limbah eksploitasi hutan. Jurnal Penelitian Hasil Hutan 3 (1): 27-31

Rachman \& Malik. 2011. Pemanfaatan Kayu Limbah Pemanenan Hutan. Suatu Tinjauan Dalam Rangka Optimasi Pemanfaatan Sumber Daya Hutan. Info Hasil Hutan 6 (1): 17-24. 